\title{
Degradation Kinetics of Three Veterinary Antibiotics in Composted and Stockpiled Manure
}

\author{
Sung Chul Kim*, Jae E Yang ${ }^{1}$, Yong Sik Ok ${ }^{1}$, Doug Young Jung, and Kenneth Carison ${ }^{2}$ \\ Department of Bio Environmental Chemistry, Chungnam National University, Daejeon 305-764, Korea \\ ${ }^{1}$ Department of Biological Environment, Kangwon National University, Chuncheon 200-701, Korea \\ ${ }^{2}$ Department of Civil and Environmental Engineering, Colorado State University, Fort Collins, CO, 80523
}

\begin{abstract}
Two typical animal waste management practices, composting and stockpiling, were evaluated for their effect on the degradation of three veterinary antibiotics (VAs), chlortetracycline (CTC), tylosin (TYL), and monensin (MNS). The VAs were applied to horse manure plots subject to composting or stockpiling, and core samples were collected over a period of time. Selected buffer solutions were used to extract the VAs and analysis for concentration was conducted with solid phase extraction (SPE) followed by high performance liquid chromatography tandem mass spectrometry (HPLC/MS/MS) technique. The VAs demonstrated rapid dissipation within ten days followed by a gradual decrease in concentration until the end of the experimental period (141 days). All three VAs degraded more rapidly in the composting samples than in the stockpiling samples, particularly between 20 and 60 days of the observation period. Degradation of the three VAs generally followed a first-order kinetic model, and a fitted model with a calculated rate constant was determined for each treatment. TYL in composting showed the fastest degradation, with a calculated rate constant of 0.91 day $^{-1}$; the slowest degradation was exhibited by MNS in stockpiling, with rate constant of 0.17 $\mathrm{day}^{-1}$. Calculated correlation coefficients ranged from 0.89 to 0.96 , indicating a strong comelation between measured concentrations and fitted values in this study. Although concentration of TYL in composting treatment showed below detection limit during the test period, this study suggests that composting can reduce animal waste contaminants prior to field application as fertilizer.
\end{abstract}

Key words: Veterinary antibiotics, Degradation, Composting, Stockpiling, Animal waste treatment

\section{Introduction}

Veterinary antibiotics (VAs) are used in animals for both therapeutic and non therapeutic purposes (e.g. growth-promotion purpose). According to recent reports, the estimated annual VA application for non-therapeutic purpose in the U.S is 25 million pounds $-77 \%$ of the total consumption of human and animal antibiotics (Mellon et al., 2001). Given this enormous quantity of VAs and the fact that more than $70 \%$ of these antibiotics can be excreted as parent compounds or metabolites, there is a high chance of finding residuals of VAs in the environment (Kim and Carlson, 2005).

The majority of excreted VAs is found in manure, and a considerable amount can be introduced to soil, ground-

\footnotetext{
Received : January 19. 2012 Accepted : February 8. 2012

*Corresponding author : Phone: +82428216737

E-mail: sckim@cnu.ac.kr
}

water, and surface water by spreading contaminated manure as fertilizer, through accidental leakage from storage, and overflowing as runoff. Studies measuring residuals of several VAs in different environmental compartments have found relatively higher concentrations detected in animal waste (Blackwell et al., 2004; Campagnolo et al., 2002; Christian et al., 2003; Haller et al., 2002; Kolz et al., 2005; Liguoro et al., 2003; Schlusener et al., 2003) than in soil (Aga et al., 2005; Blackwell et al., 2004; Christian et al., 2003; HallingSorensen et al., 2005; Hamscher et al., 2002; Jacobsen et al., 2004; Liguoro et al., 2003) and in surface water (Campagnolo et al., 2002; Christian et al., 2003; Zhu et al., 2001).

Currently, two techniques for managing animal waste on site are composting and stockpiling. The primary mechanism involved in composting is the enhanced aerobic decomposition of organic matter by microorganisms, using adequate moisture and temperature 
(Liang et al., 2003). A recent study reported the effect of composting on the dissipation of endocrine disruptor chemicals (EDCs) $17 \beta$-estradiol and testosterone in poultry manure. This report concluded that $84 \%$ and $90 \%$ of the quantity of $17 \beta$-estradiol and testosterone, respectively, diminished over a period of 139 days (Hakk et al., 2005). While this study indicated that composting could not eliminate the EDCs completely, this technique is efficient in removing organics.

The stockpiling technique involves piling the manure without any active treatment, in an anaerobic state. Although composting can generate greenhouse gas such as ammonia, methane, carbon dioxide and might require more labor and time than stockpiling, composting is a more effective method than stockpiling in destroying pathogens, decreasing bulk density, and enriching nutrients.

With manure regarded as a main source of VA residuals in the environment, more information about the fate of VAs in manure is needed to identify animal waste treatment options. The purpose of this study was to determine the fate of excreted VAs during composting and stockpiling and to provide a possible means of reducing VA residuals prior to manure application in field as fertilizer.

\section{Materials and Methods}

Chemicals and veterinary antibiotics The target veterinary antibiotics (VAs) chlortetracycline, tylosin, and monensin (90-95\%, sodium salt), and HPLC-grade methanol solvent $(99.9 \%)$ were purchased from SigmaAldrich Co. (St. Louis, MO). Other chemicals used
- analytical grade formic acid (99\%), ammonium hydroxide ( $29 \%$ by weight), citric acid-monohydrate, sodium phosphate-dibasic anhydrous, and disodium ethylene diaminetetraacetic acid $\left(\mathrm{Na}_{2}\right.$ EDTA $)$ - were purchased from Fisher Scientific (Fair Lawn, NJ). Each VA stock solution $\left(100 \mathrm{mg} \mathrm{L}^{-1}\right)$ was prepared in methanol monthly and stored at $4^{\circ} \mathrm{C}$. Working solutions of $5 \mathrm{mg} \mathrm{L}^{-1}$ and $0.5 \mathrm{mg} \mathrm{L}^{-1}$, diluted from stock solution, were prepared fresh immediately prior to use. The $3 \mathrm{ml} / 60 \mathrm{mg}$-capacity HLB (HydrophillicLipophillic-Balance) cartridges used for solid phase extraction (SPE) were purchased from Water Oasis Co. (Milford, MA); Milli-Q water purification system from Millipore (Billerica, CA) was used when DI water was required.

Study plots Horse manure was chosen for the study medium because horses are not given antibiotics as growth promoters. Horse manure was collected from the Colorado State University Equine Center and either composted or stockpiled in three replicate piles of $5.4 \mathrm{~m}^{3}$ as windrow type. Two control piles, one for composting and one for stockpiling, were set up and not spiked with antibiotics. Composted manure was amended with $1.5 \mathrm{~m}^{3}$ of leaves and alfalfa. After establishing the treatment plots, baseline samples from each of the eight plots were analyzed by the Soil, Water and Plant Testing Lab (Colorado State University, Fort Collins, CO) for physicochemical properties. As shown in Table 1, average moisture content was 31.7\% for composting piles and $28.1 \%$ for stockpiling plots. The calculated average $\mathrm{C} / \mathrm{N}$ ratio was 13 and 15 for composting and stockpiling plots, respectively.

The six treatment plots were spiked at approximately

Table 1. Physicochemical properties of horse manure in each plot.

\begin{tabular}{ccccccccc}
\hline \hline Plot $^{\mathrm{a}}$ & $\begin{array}{c}\text { Moisture } \\
(\%)\end{array}$ & $\mathrm{pH}$ & $\begin{array}{c}\mathrm{EC} \\
(\mathrm{dS} \mathrm{m})\end{array}$ & $\begin{array}{c}\mathrm{C} \\
(\%)\end{array}$ & $\begin{array}{c}\mathrm{N} \\
(\%)\end{array}$ & $\begin{array}{c}\mathrm{NH}_{4}-\mathrm{N} \\
\left(\mathrm{mg} \mathrm{kg}^{-1}\right)\end{array}$ & $\begin{array}{c}\mathrm{NO}_{3}-\mathrm{N} \\
\left(\mathrm{mg} \mathrm{kg}^{-1}\right)\end{array}$ & $\begin{array}{c}\mathrm{K} \\
\left(\mathrm{mg} \mathrm{kg}^{-1}\right)\end{array}$ \\
\hline Control & 31.1 & 8.2 & 3.8 & 7.5 & 0.6 & 3.9 & 207.8 & $14,000.0$ \\
C-1 & 30.8 & 8.3 & 4.3 & 11.5 & 0.8 & 21.5 & 167.7 & $14,685.0$ \\
C-2 & 32.1 & 8.2 & 4.0 & 7.6 & 0.6 & 14.5 & 206.7 & $13,770.0$ \\
C-3 & 33.0 & 8.2 & 4.1 & 8.9 & 0.7 & 8.2 & 207.2 & $14,495.0$ \\
\hline Control & 30.6 & 8.4 & 5.5 & 13.2 & 0.9 & 312.6 & 191.7 & $18,780.0$ \\
S-1 & 29.4 & 8.3 & 4.9 & 10.4 & 0.7 & 291.6 & 291.2 & $14,590.0$ \\
S-2 & 29.3 & 8.5 & 4.8 & 12.5 & 0.9 & 411.4 & 291.6 & $18,305.0$ \\
S-3 & 23.2 & 8.3 & 4.2 & 12.8 & 0.8 & 378.7 & 252.3 & $16,500.0$ \\
\hline
\end{tabular}

${ }^{\mathrm{a}} \mathrm{C}$ and $\mathrm{S}$ denote the composting and stockpiling respectively. 
$0.328 \mathrm{mg} \mathrm{kg}^{-1}$ with CTC and TYL dissolved in water and sprayed onto the piles while mixing and with MNS ground in a blender and sprinkled over the piles while mixing and watering. Two different mixing methods were used because of insolubility property of MNS. Watering and turning was conducted three times during the study (day 4, day 17, and day 38) and stopped after temperature was dropped below $10^{\circ} \mathrm{C}$.

The stockpiles initially heated to temperatures greater than $52^{\circ} \mathrm{C}$ by the third week of the experiment. These temperatures dropped to less than $40^{\circ} \mathrm{C}$ by the fourth week and decreased steadily throughout the remainder of the study. The composted piles heated up more gradually, reaching temperatures greater than $50^{\circ} \mathrm{C}$ during the fourth week of the study and maintained temperatures at or greater than $40^{\circ} \mathrm{C}$ for at least two more weeks. Plots of both treatments had dropped to temperatures less than $10^{\circ} \mathrm{C}$ by the eighth week of the experiment.

Sample collection and preparation Samples were collected in ten locations from each pile at each sampling event using a coring device from approximately $20 \mathrm{~cm}$ inside of windrow. The multiple samples collected from each pile were composited and slurried $(25 \mathrm{~g}$ of sample $+25 \mathrm{~mL}$ of DI water) to form a homogenous mixture for subsequent antibiotic analysis. Sampling was performed every week during the first eight weeks of the study and a final sample was taken at day 141 of the study. Three different samples were collected and composited to make one sample in each plot.

Analysis of veterinary antibiotics Analysis was performed on samples collected from eight selected sampling events. Prepared slurry samples contained in $50 \mathrm{~mL}$ sterilized centrifuge tubes were thoroughly mixed immediately before analysis, then a $1 \mathrm{~g}$ aliquot from each tube was transferred to a $40 \mathrm{~mL}$ Teflon tube. Two different buffer solutions were used to extract the target VAs from solid phase to liquid phase: Mcllvaine buffer solution ( $\mathrm{pH}$ 4.0) was used for CTC, and $1 \mathrm{M}$ ammonium hydroxide buffer solution $(\mathrm{pH}$ 10.0) titrated with formic acid was used for TYL and MNS. For CTC extraction only, $200 \mu \mathrm{L}$ of $\mathrm{Na}_{2}$ EDTA ( $5 \% \mathrm{w} / \mathrm{v}, 1 \mathrm{mmol}$ in solution) was added to complex the metal in solution. After adding $20 \mathrm{~mL}$ of the appropriate buffer, samples were shaken vigorously (Model No-
4626, Lab-line instrument) for 20 minutes at 400 rpm. Shaken samples were centrifuged (IEC Clinical Centrifuge, International Equipment Co., Needham Hights, MA) for ten minutes at $4000 \mathrm{rpm}$ to separate liquid and solid phases. The supernatant from each sample was filtered through a $0.2 \mu \mathrm{m}$ glass fiber filter and decanted into another $40 \mathrm{~mL}$ glass vial. The filtered sample was kept at $4{ }^{\circ} \mathrm{C}$ until SPE clean up. The remaining solid sample was re-extracted with the same procedure described above to yield $40 \mathrm{~mL}$ of total volume. SPE and concentration procedures were conducted as described in a previous report (Kim and Carlson, 2006; Kim and Carlson, 2007).

Average measured moisture content of the slurries was $71 \%$. After this determination, all measured concentrations were determined as dry weight.

High performance liquid chromatography/tandem mass spectrometry (HPLC/MS/MS) High performance liquid chromatography (HPLC) with an HP 1100 Series Liquid Chromatography (Agilent, Palo Alto, CA) was used to separate the VAs. The analytical column was an XTerra MS $\mathrm{C}_{18}$ column (Waters, Milliford, MA), $2.1 \times 50 \mathrm{~mm}$ (inner diameter $\times$ length, $2.5 \mu \mathrm{m}$ pore size, end capped) equipped with a $\mathrm{C}_{18}$ guard column (Phenomenex, Torrence, CA, USA) to filter any particulates from the sample. Injection volume was $20 \mu \mathrm{L}$ for all VAs. Ten minutes of post-run time was allowed to equilibrate the column between each analysis. A ThermoFinnigan LCQ Duo Ion Trap Mass Spectrometer (ThermoQuest, Woburn, MA) equipped with a heated capillary interface and electrospray ionization (ESI) was used for mass spectrometric (MS) analysis. Optimization of MS was performed with the LCQ Duo syringe pump at a flow rate of $5 \mu \mathrm{L} \mathrm{min}{ }^{-1}$ by infusing a standard solution of each compound $(10 \mu \mathrm{M})$. Optimized HPLC conditions and MS parameters are summarized in Table 2.

Quality assurance Recovery and limit of quantification (LOQ) determinations were conducted with raw horse manure analyzed prior to treatment to verify the absence of residual antibiotics. To determine analysis recovery, measured sample detection response was compared to the detection response of the same spike concentration in $5 \mathrm{~mL}$ of methanol extractant. Detection response was calculated using the curve area of the internal standard, simatone, and the curve 
Table 2. Compound-specific optimized HPLC parameters and optimized MS parameters.

\begin{tabular}{|c|c|c|c|}
\hline \multicolumn{4}{|c|}{ Optimized HPLC conditions } \\
\hline & $\begin{array}{c}\text { Column temp. } \\
\left({ }^{\circ} \mathrm{C}\right)\end{array}$ & $\begin{array}{l}\text { Flow rate } \\
\left(\mathrm{mL} \min ^{-1}\right)\end{array}$ & Mobile phase conditions ${ }^{\mathrm{a}}$ \\
\hline CTC & 15 & 0.32 & $\begin{array}{l}\text { A: } 96 \%+B: 4 \%(0 \min ) \rightarrow \\
\text { A: } 70 \%+\text { B: } 30 \%(29 \min ) \rightarrow \\
\text { A: } 96 \%+B: 4 \%(30 \mathrm{~min})\end{array}$ \\
\hline TYL & 45 & 0.32 & $\begin{array}{l}\text { A: } 80 \%+\text { B: } 20 \%(0 \mathrm{~min}) \rightarrow \\
\text { A: } 65 \%+\text { B: } 35 \%(13 \mathrm{~min}) \rightarrow \\
\text { A: } 96 \%+\text { B: } 4 \%(14 \mathrm{~min})\end{array}$ \\
\hline MNS & 15 & 0.25 & $\begin{array}{l}\text { A: } 50 \%+\mathrm{C}: 50 \%(0 \mathrm{~min}) \rightarrow \\
\text { A: } 10 \%+\mathrm{C}: 90 \%(19 \mathrm{~min}) \rightarrow \\
\text { A: } 50 \%+\mathrm{B}: 50 \%(20 \mathrm{~min})\end{array}$ \\
\hline
\end{tabular}

Optimized MS conditions

Nitrogen gas for drying and nebuilizing

Spray voltage: $4.5 \mathrm{~V}$

Capillary voltage: $21 \mathrm{~V}$

Capillary temperature: $165^{\circ} \mathrm{C}$

${ }^{a}$ Mobile phase A: $99.9 \%$ water $+0.1 \%$ formic acid;

Mobile phase B: $99.9 \%$ acetonitrile $+0.1 \%$ formic acid;

Mobile phase C: $100 \%$ methanol.

Table 3. Summary of analysis recovery and limit of quantification (LOQ).

\begin{tabular}{lccc}
\hline \hline Compound & \multicolumn{2}{c}{ Recovery $(\%)^{\mathrm{a}}$} & $\begin{array}{c}\mathrm{LOQ}^{\mathrm{b}} \\
\left(\mathrm{mg} \mathrm{kg}^{-1}\right)\end{array}$ \\
\cline { 2 - 4 } CTC & $0.03\left(\mathrm{mg} \mathrm{kg}^{-1}\right)$ & $\left.0.09(\mathrm{mg} \mathrm{kg})^{-1}\right)$ & 0.0012 \\
TYL & 98.9 & 94.6 & 0.001 \\
MNS & 92.4 & 93.1 & 0.0007 \\
\hline
\end{tabular}

${ }^{a}$ Average of duplicated experiments.

${ }^{\mathrm{b}}$ Calculated standard deviation of three individual samples spiked with $0.001 \mathrm{mg} \mathrm{kg}^{-1}$ in control samples was multiplied by the one sided Student-t variate at $95 \%$ confidence intervals.

area of each sample, as determined by HPLC-MS/MS analysis. Simatone was used as an internal standard because it eluted within the same chromatographic timeframe as the analytes and responded well to positive electrospray ionization (Lindsey et al., 2001). Further, there is no noticeable matrix effect with simatone, a criterion for this complex study matrix. Two different concentrations, $0.03 \mathrm{mg} \mathrm{kg}^{-1}$ and 0.09 $\mathrm{mg} \mathrm{kg}{ }^{-1}$, were examined; recovery ranged from $94 \%$ to $98 \%$, depending on the VAs.

Limit of quantification was assessed in the statistical manner described in a previous report (Zhu et al., 2001). Calculated LOQ varied from 0.0007 to 0.0012 $\mathrm{mg} \mathrm{kg}{ }^{-1}$. A summary of recovery and LOQ is shown in Table 3. A linear calibration curve was constructed from 0.001 to $0.18 \mathrm{mg} \mathrm{kg}^{-1}$ with $\mathrm{r}>0.99$.

\section{Results and Discussion}

Degradation profile of antibiotics with time Initial recovery concentrations of the target VAs in three treatment replicates averaged $0.317 \mathrm{mg} \mathrm{kg}^{-1}$ and 0.315 $\mathrm{mg} \mathrm{kg}^{-1}$ for CTC in composting and stockpiling, respectively; $0.18 \mathrm{mg} \mathrm{kg}^{-1}$ and $0.228 \mathrm{mg} \mathrm{kg}^{-1}$ for TYL; and $0.249 \mathrm{mg} \mathrm{kg}^{-1}$ and $0.243 \mathrm{mg} \mathrm{kg}^{-1}$ for MNS. Although recovered concentration at time 0 for TYL was much lower than the spiked concentration of $0.328 \mathrm{mg} \mathrm{kg}^{-1}$, initial measurement of the other two target compounds was in good agreement with the spiked concentration in both management treatments. Variance of the three replicate measurements at time 0 ranged from 3 to $30 \%$, with the greatest variance observed for TYL in stockpiling. 
(A)

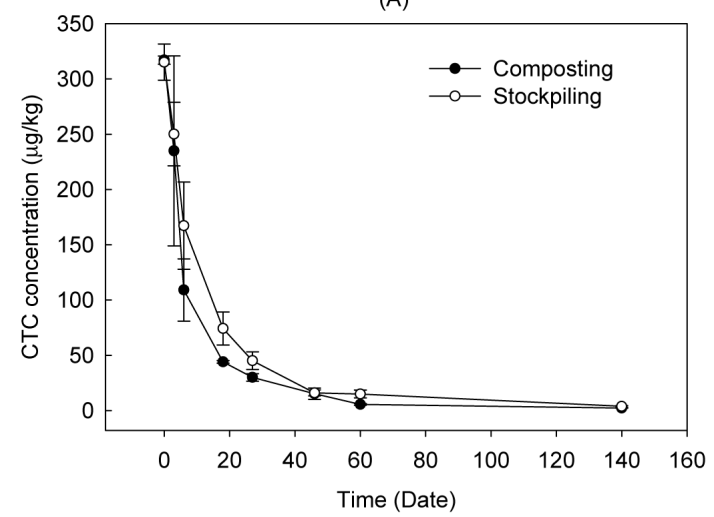

(B)

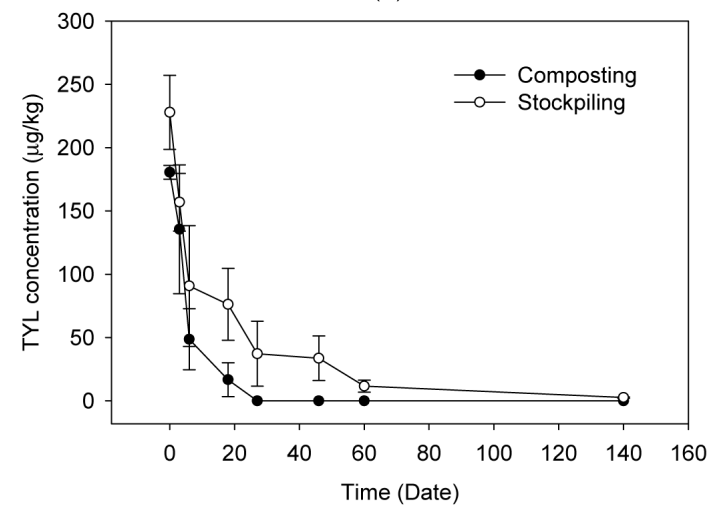

(C)

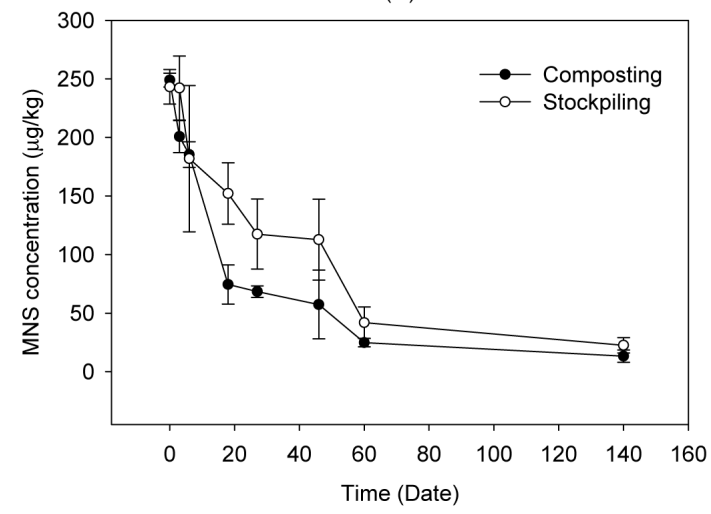

Fig. 1. Measured Concentration of CTC (A), TYL (B), and MNS (C) in Composting and Stockpiling Samples with Time (error bar reflects standard deviation of three plots).

Degradation of the VAs exhibited a similar trend with time. As shown in Fig. 1, all three VAs rapidly dissipated within the first ten days and gradually decreased until the end of the observation period. The percentage of degradation at the end of experiment in the two management treatments, composting and stockpiling, was 99.3 and 98.8, respectively, for CTC; 100 and 98.8 for TYL; and 94.7 and 90.7 for MNS. While elimination of all three VAs was incomplete in five of the six treatment plots by the end of the experiment, TYL in the composting plot was completely

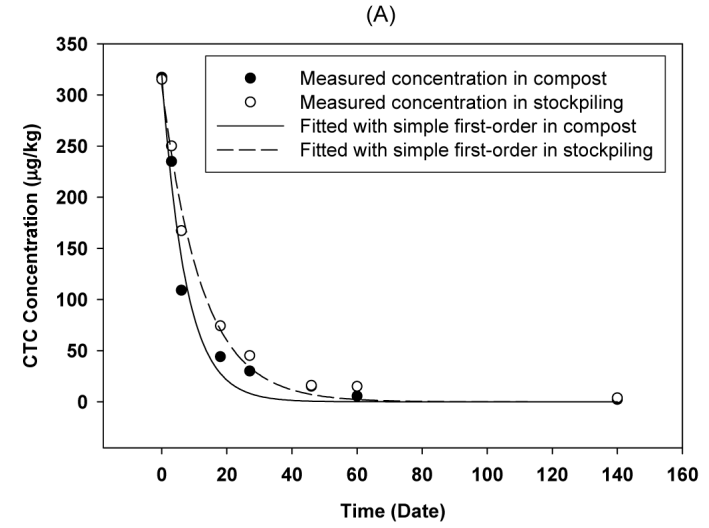

(B)

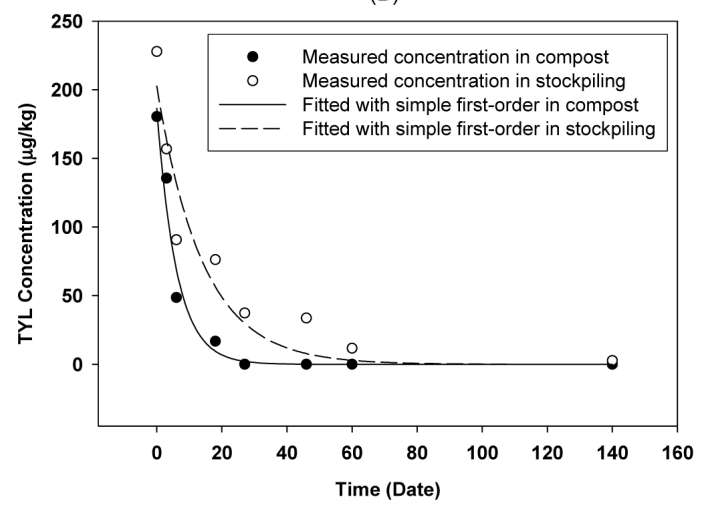

(C)

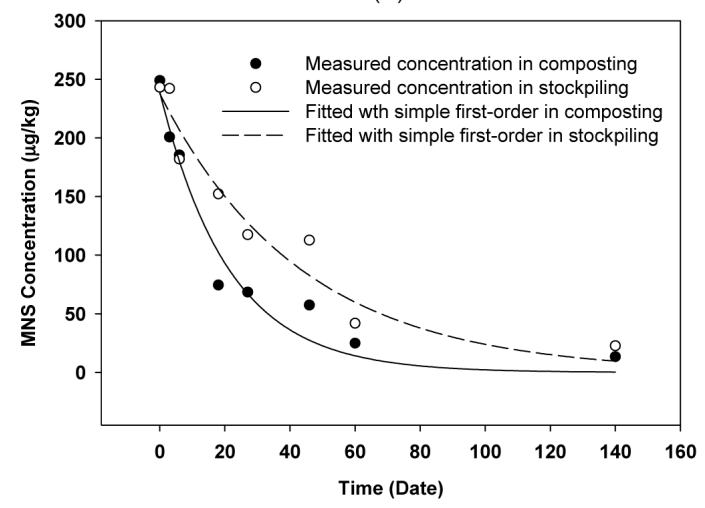

Fig. 2. Fitted First-Order Model for CTC (A), TYL (B), and MNS $(\mathrm{C})$ in Composting and Stockpiling.

depleted by 27 days. MNS showed the slowest degradation rate and the highest residuals, $0.013 \mathrm{mg} \mathrm{kg}^{-1}$ and $0.023 \mathrm{mg} \mathrm{kg}^{-1}$ (dry weight) in the composting and stockpiling treatment plots, respectively, at the end of experiment. Rapid degradation was observed for TYL in both treatments, compared to the other two compounds; moderate degradation of CTC was observed.

While initial degradation (up to ten days) and final concentrations of the three VAs were similar between the two waste management treatments, composting showed more rapid degradation of all three VAs from 20 to 60 days of the observation period. This result suggests that composting management might 
be more efficient in the dissipation of VA residuals when contaminated animal waste is stored for a short period of time.

First-order kinetic model The degradation of the three VAs in composting and stockpiling management was fitted with a simple first-order kinetic model (Eq. 1) commonly used to frame the dissipation of environmentally related contaminants.

$$
\frac{d C}{d t}=-k C
$$

where $\mathrm{C}$ is the measured concentration $\left(\mathrm{mg} \mathrm{kg}^{-1}\right)$ at time $\mathrm{t}$ (day) and $\mathrm{k}$ is the pseudo rate constant $\left(\mathrm{day}^{-1}\right)$.

The first-order rate constant, $\mathrm{k}$, represents the contribution of chemical and biological reactions in the dissipation of compounds; a higher $\mathrm{k}$ value signals faster degradation. Integrating both sides of the firstorder kinetic model shown in Eq. 1 yields the degradation kinetic model shown in Eq. 2.

$$
C_{t}=C_{0} e^{-k t}
$$

where $\mathrm{C}_{0}$ is the initial concentration at time 0 and $\mathrm{C}_{\mathrm{t}}$ is the concentration at time $\mathrm{t}$.

The fitted first-order kinetic model for the three VAs in both treatments is shown in Fig. 2. The calculated rate constant $(\mathrm{k})$ and correlation coefficient are presented in Table 4.

In the degradation of CTC, a slightly higher rate constant was calculated for composting, $0.034 \mathrm{day}^{-1}$, than stockpiling, 0.031 day $^{-1}$, indicating slightly more rapid degradation in composting. However, a higher correlation coefficient was calculated between the experimental data and the fitted model for stockpiling. This result suggests that the degradation rate at each sampling event was more variable in composting than stockpiling, decreasing accuracy in the composting fitted model (Wang et al., 2006).

TYL degradation in composting showed the highest calculated rate constant, $0.091 \mathrm{day}^{-1}$, and a much lower calculated rate constant for stockpiling. Previous investigation of the degradation of TYL in manure reported that TYL depleted fairly fast in anaerobic conditions and even faster in aerobic conditions (Kolz et al., 2005). The majority, 90\%, of initially applied TYL dissipated in less than five days after the beginning of aerated composting management in the present study; an observation that supports these previously reported results.

Of the three VAs, the lowest rate constant was calculated for MNS in both management treatments. As seen with the other two compounds, composting showed more rapid degradation than stockpiling management; both treatments yielded a correlation coefficient showing the fitted model closely reflected the experimental data.

Time for half life of the three VAs was calculated according to follow equation:

$$
t_{50 \%}=-\frac{0.693}{k}
$$

Calculations showed that TYL in composting exhibited the shortest half-life, 7.6 days, while MNS in stockpiling showed the longest, 39.8 days. Previous investigation documented a 25-58 days half-life for CTC and 4976 days for TYL in soil (Halling-Sorensen et al., 2005), a much longer half-life than that observed in the present study. Another investigation comparing the half-life of CTC, TYL, and MNS reported a much shorter half-life in manure-amended and manure-free soil (Carlson and Mabury, 2006); in that study, the calculated half-life in manure-amended soil was $24,4.5$, and 3.3 days for CTC, TYL, and MNS, respectively,

Table 4. Calculated parameters for fitting the degradation of three VAs in waste composting and stockpiling.

\begin{tabular}{cccc}
\hline \hline Antibiotic/Waste Management & Rate constant, $\mathrm{k}\left(\mathrm{day}^{-1}\right)$ & Correlation coefficient, $\mathrm{r}$ & $\mathrm{t}_{1 / 2}($ day $)$ \\
\hline CTC Composting & 0.034 & 0.89 & 20.3 \\
CTC Stockpiling & 0.031 & 0.94 & 22.4 \\
TYL Composting & 0.091 & 0.96 & 7.60 \\
TYL Stockpiling & 0.030 & 0.91 & 23.5 \\
MNS Composting & 0.021 & 0.93 & 33.8 \\
MNS Stockpiling & 0.017 & 0.96 & 39.8 \\
\hline
\end{tabular}


and 21, 6.1, and 3.8 days in manure-free soil. The persistence order, CTC > TYL > MNS, in the latter study also differed from that observed in the present study, MNS $>$ CTC $>$ TYL. The difference might be explained by the different microorganisms present in soil and manure that would control the degradation rate for different antibiotics.

\section{Conclusions}

Dissipation of veterinary antibiotic residuals with commonly used animal waste management practices, composting and stockpiling, was evaluated. The result of recovery study, $92-99 \%$ of the recovery from initially spiked antibiotics in horse manure, showed that analytical method adapted in this study was suitable to measure sub-microgram concentration of antibiotics in manure.

Composting showed more efficient degradation of the target VAs than stockpiling. Calculated half-life of the target VAs ranged from 8 to 34 days for composting and 20 to 40 days for stockpiling, depending on the antibiotic compound. Although incomplete elimination was observed in most of the treatment plots during the experimental period at least $95 \%$ of the applied antibiotics had degraded over this time. The results of this study show that composting can efficiently reduce the residuals of veterinary antibiotics in manure prior to field application and might be useful in assessing environmental contamination risk in future investigations.

\section{References}

Aga, D.S., S. O'connor, S. Ensley, J.O. Payero, D. Snow and D. Tarkalson. 2005. Determination of the persistance of tetracycline antibiotics and their degradates in manureamended soil using Enzyme-Linked Immunosorbent Assay and liquid chromatography-mass spectrometry. J. Agric. Food Chem. 53:7165-7171.

Blackwell, P.A., H.H. Lutzhoft, H.P. Ma, B. Halling-Sorensen, A.B.A. Boxwell and P. Kay. 2004. Ultrasonic extraction of veterinary antibiotics from soils and pig slurry with SPE clean-up and LC-UV and fluorescence detection. Talanta 64:1058-1064.

Campagnolo, E.R., K.R. Johnson, A. Karpati, C.S. Rubin, D.W. Kolpin, M.T. Meyer and J.E. Esteban. 2002. Antimicrobial residuals in animal waste and water resources proximal to large-scale swine and poultry feeding operations. Sci. Total Environ. 299:89-95.

Carlson, J.C. and S.A. Mabury. 2006. Dissipation kinetics and mobility of chlortetracycline, tylosin, and monensin in an agricultural soil in Northumberland county, Ontario, Canada. Environ. Toxicol. Chem. 25:1-10.

Christian, T., R.J. Schneider, H.A. Farber, D. Skutlarek, M.T. Meyer and H.E. Goldbach. 2003. Determination of antibiotics residuals in manure, soil, and surface water. Acta Hydroch. Hydrob. 31:36-44.

Hakk, H., P. Millner and G. Larsen. 2005. Decrease in watersoluble 17b-estradiol and testosterone in composted poultry manure with time. J. Environ. Qual. 34:943-950.

Haller, M.Y., S.R. Muller, C.S. McArdell, A.C. Alder and M.J.-F. Suter. 2002. Quantification of veterinary antibiotics (sulfonamides and trimethoprim) in animal manure by liquid chromatography-mass spectrometry. J. Chromatogr. A 952: 111-120.

Halling-Sorensen, B., A.M. Jacobsen, J. Jensen, G. Sengelov, E. Vaclavik and F. Ingerslev. 2005. Dissipation and effects of chlortetracycline and tylosin in two agricultural soils: A field-scale study in southern Denmark. Environ. Toxicol. Chem. 24:802-810.

Hamscher, G., S. Sczesny, H. Hoper and H. Nau. 2002. Determination of persistent tetracycline residues in soil fertilized with liquid manure by high performance liquid chromatography with electrospray ionization tandem mass spectrometry. Anal. Chem. 74:1509-1518.

Jacobsen, A.M., B. Halling-Sorensen, F. Ingerslev and S.H. Gansen. 2004. Simultaneous extraction of tetracycline, macrolide and sulfonamide antibiotics from agricultural soils using pressurised liquid extraction, followed by solidphase extraction and liquid chromatography-tandem mass spectrometry. J. Chromatogr. A 1038:157-170.

Kim, S.C. and K. Carlson. 2005. LC-MS ${ }^{2}$ for quantifying trace amounts of pharmaceutical compounds in soil and sediment matrices. TrAC, Trends in Anal. Chem. 24:635-644.

Kim, S.C. and K.H. Carlson. 2006. Occurrence of ionophore antibiotics in water and sediments of a mixed-landscape watershed. Water Res. 40:2549-2560.

Kim, S.C. and K.H. Carlson. 2007. Quantification of human and veterinary antibiotics in water and sediment using SPE/ LC/MS/MS. Anal. Bioanal. Chem. 387:1301-1315.

Kolz, A.C., B. Moorman, S.K. Ong, K.D. Scoggin and E.A. Douglass. 2005. Degradation and metabolite production of tylosin in anaerobic and aerobic swine-manure lagoons. Water Environ. Res 77:49-56.

Liang, C., K.C. Das and R.W. McClendon. 2003. The influence of temperature and moisture contents regimes on the aerobic microbial activity of a biosolids composting blend. Bioresour. Technol. 86:131-137.

Liguoro, M.D., V. Cibin, F. Capolongo, B. Halling-sorensen and C. Montesissa. 2003. Use of oxytetracycline and tylosin in intensive calf farming: evaluation of transfer to manure and soil. Chemosphere 52:203-212.

Lindsey, M.E., M. Meyer and E.M. Thurman. 2001. Analysis of trace levels of sulfonamides and tetracycline antimicrobials in groundwater and surface water using solid-phase extraction and liquid chromatography/mass spectrometry. Anal. Chem. 
73:4640-4646.

Mellon, M., C. Benbrook and K.L. Benbrook. 2001. Hogging it: Estimation of antimicrobial abuse in livestock. Union of Concerned Scientists.

Schlusener, M.P., K. Bester and M. Spiteller. 2003. Determination of antibiotics such as macrolide, ionophores and tiamulin in liquid manure by HPLC-MS/MS. Analytical and Bioanalytical Chemistry 375:942-947.
Wang, Q., M. Guo and S. Yates. 2006. Degradation kinetics of manure-derived sulfadimethoxine in amended soil. J. Agric. Food Chem. 54:157-163.

Zhu, J., D.D. Snow, D.A. Cassada, S.J. Monson and R.F. Spalding. 2001. Analysis of oxytetracycline, tetracycline, and chlorotetracycline in water using solid-phase extraction and liquid chromatography tandem mass spectrometry. J. Chromatogr. A 928:177-186. 